\title{
Article
}

\section{Accuracy of eddy-current and radar methods used to reinforcement detection}

\author{
Łukasz Drobiec ${ }^{1}$, Radosław Jasiński ${ }^{2}$ and Wojciech Mazur ${ }^{3 *}$ \\ 1 Silesian University of Technology, Department of Building Structures; ul. Akademicka 5, 44-100 Gliwice, \\ Poland, lukasz.drobiec@polsl.pl \\ 2 Silesian University of Technology, Department of Building Structures; ul. Akademicka 5, 44-100 Gliwice, \\ Poland, radoslaw.jasinski@polsl.pl \\ 3 Silesian University of Technology, Department of Building Structures; ul. Akademicka 5, 44-100 Gliwice, \\ Poland, wojciech.mazur@polsl.pl \\ * Correspondence: wojciech.mazur@polsl.pl; Phone No. +48 32 237-11-27
}

\begin{abstract}
Currently, the most often NDT methods used in practice to non-destructive rebar location in structures are: electromagnetic and radar methods. Both methods have some advantages, disadvantages and limitations. In work, an attempt to describe the possibilities of the particular methods with emphasizing their advantages and limitations has been made. The results of the tests conducted on a lintel beam made of AAC reinforced with small diameter rebars and with rebars placed close together have been presented. The reinforcement has been tested with two different electromagnetic scanner and a GPR device. The received results of eddy-current tests have been compared with the results of NDT tests. It has revealed that NDT tests done in this kind of element allow the correct assessment of the concrete cover but can give different results in case of shape and number of rebars.
\end{abstract}

Keywords: NDT Methods, Rebar location, Eddy-current method, GPR method

\section{Introduction}

The yield point or tension strength of the reinforcement steel are the expected values which are determining in case of existing reinforced structure. When designing repair or reinforcement need analytical testing of load-bearing or defining the durability, in this case, apart from strength features, information of the reinforcement geometry and its location in the element are also needed. The geometry of the rebars might be obtained with the traditional method, doing outcrops or with non-destructive testing [1, 2]. NDT methods are useful especially in case when the surface or number of elements necessary for testing are numerous. Electromagnetic and radar methods are currently the most often used NDT methods for detection of the reinforcement in the structure $[2,3$, 4]. Both methods have their advantages and disadvantages. It can be assumed that advantages of the electromagnetic method are: the accuracy of the measurement and the possibility to determine the diameter of the reinforcement. However, there are some disadvantages of it like short range and some errors triggered by resolution what is important when rebars are close together(lap splices, bundles of bars). The advantage of the radar method is the opportunity of the reinforcement location at great depths but there are also more disadvantages like difficulties with the diameter measurements and also some measurement errors of the damp structures. Despite continuous development, electromagnetic and radar methods are still burdened by some restrictions. In this article, some difficulties with the location and reinforcement measurement with radar and electromagnetic method tried to be depicted. There have been tested some reinforced lintel beams made of AAC with three different types of measurement devices. 


\section{NDT methods accuracy and range of possibilities}

According to definition [5] accuracy is a compatibility level between the obtained result of the single measurement and the expected value related to systematic and accidental errors. The accuracy of the electromagnetic tests depends especially on location depth, spacing, placing the rebars toward the direction of scanning and also the type of reinforcement and the quality of the concrete surface $[6,7]$. The influence on the accuracy of the tests has also the implemented type of spectral analysis and compensation procedures of the systematic measurement errors. .

The depth of the bars location has the significant influence on accuracy of the diameter measurement and even on accuracy of the bars location itself. The maximum depth of reinforcement detection depends on the rebars diameter. In case of using unusual diameter in construction $6 \div 25$ $\mathrm{mm}$, depending on device which is used, the biggest depth, on which the reinforcement might be detected is $100 \div 200 \mathrm{~mm}$. Obviously, the closer the rebars are located to the scanning surface the accuracy of the measured diameter and the actual diameter is greater. The acceptable measurement accuracy ( $5 \%$ ) of the reinforcement diameter is obtained by putting the rebars to a depth of around $60 \mathrm{~mm}$.

The measurement is made with the single-frequency or multi-frequency method. In the construction tests of the steel reinforced concrete, multi-frequency signals with sinusoidal characteristic are often used. Sinusoidal excitation signal emitted in the depth of the structure, depends on time $t$. That is why, excitation $\mathrm{W}(\mathrm{t})$ might be written $[8,9]$ by harmonic function:

$$
W(t)=\sum_{1}^{N} w_{i} \sin \left(\omega_{w i} t+\varphi_{w i}\right),
$$

where:

$w_{\mathrm{i}}$ - the amplitude of the sinusoidal extortion,

$\omega_{\mathrm{i}}$ - pulsation of the sinusoidal extortion,

$\varphi_{w i}$ - phase angle of the sinusoidal extortion.

Assuming that the reinforcement in the tested element would trigger the linear changes of the extortion function, signal $\mathrm{y}(\mathrm{t})$ received by measuring coil is :

$$
y(t)=\sum_{1}^{N} k_{w i} w_{i} \sin \left(\omega_{y i} t+k_{i \varphi} \varphi_{y i}\right),
$$

where:

$k_{\mathrm{wi}}$ - the amplitude factor of the received sinusoidal wave,

$\omega_{\mathrm{yi}}$ - pulsation of the received sinusoidal wave,

$k_{\mathrm{i} \varphi}$ - phase angle change factor of the received sinusoidal wave,

$\varphi_{y i}-$ phase angle of the received sinusoidal wave.

The assumption of a linear change of the function of sinusoidal extortion indicates that the pulsation of the excitation signal and the received signal are equal:

$$
\omega_{w i}=\omega_{y i},
$$

On this basis function $\mathrm{y}(\mathrm{t})$ might be determined according to:

$$
y(t)=\sum_{1}^{N} k_{w i} w_{i} \sin \left(\omega_{w i} t+k_{i \varphi} \varphi_{y i}\right) .
$$

The information about reinforcement geometry is included in coefficients $k_{w i} i k_{\varphi i}$. Signal $y(t)$ is registered to the probe RAM memory. Next the measuring signal is processed most often consisting in signal conversion onto digital and spectral analysis. The most important parameters in case of reinforcement measurement are amplitude sinusoidal components. Microprocessor of the 
testing device calculates and analyses measured signal amplitude components and on this basis it estimates the diameter and the depth location of the reinforcement. The processing of the measuring probes signals is often done with the usage of the inverse model based on dynamic neural nets [10].

In article [7] the plain and ribbed rebars location of 12 diameters tests have been presented. The tests were done with the usage of four different devices. It has revealed that the measured thickness of the concrete cover does not differ more than $4 \mathrm{~mm}$ and measured reinforcement diameter not more than one gradation. In work [11] the errors of the electromagnetic device measurement with dimensions 400x400×250 mm were analysed, made of high compressive strength concrete (average $71,3 \mathrm{~N} / \mathrm{mm}^{2}$ ). In each slab ,one rebar has been placed. The rebars of 12, 16, 20, 25 and $32 \mathrm{~mm}$ diameter have been used with 50 and $100 \mathrm{~mm}$ covers (in total 10 of test models). In fig. 1 the graph of the relative measurement error of the reinforcement diameter in the function of the concrete cover size has been shown. The accepted error $(<10 \%)$ with the usage of till around $40 \mathrm{~mm}$ thickness cover has been obtained. It must be emphasized that despite of relatively new work [11], the used device was not modern. The tests on the models of less compressive strength have not been done so that it is hard to define what the influence of the high compressive strength concrete was. In typical steel-reinforced concrete structures (beams, slabs, pillars), by standards covers (c $20-45 \mathrm{~mm}$ ), available in practice electromagnetic devices allow to do the tests with accuracy of the measurement less than $10 \%$. Gradation of bar diameters causes that there are some difficulties in diameter differentiation.

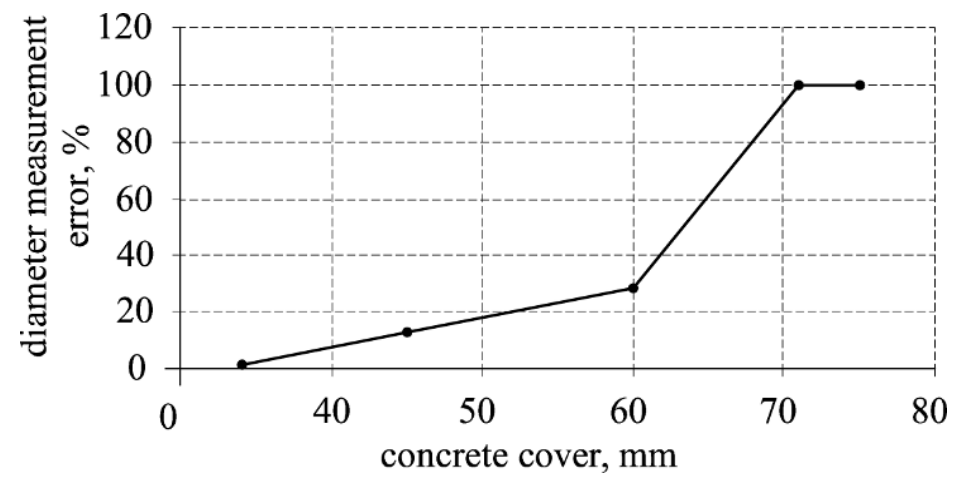

Figure 1. The error of the diameter reinforcement measurement made with electromagnetic device depending on the cover size according to [11]

In the radar method, the range in the depth of structure depends on concrete structure, kind of an antenna and size of the excited impulse frequencies $[12,13,14]$. In typical devices this range is up to $750 \mathrm{~mm}$. The image contrast obtained with radar method tests depends on relative difference between the fixed dielectric of the bordering on each other materials. There are no difficulties with the obtained image interpretation because of the considerable differences in the concrete and steel fixed values. The result of the reinforcement location tests, conducted with radar method are so called radargrams, it means, record of all reflected signals registered during passage of measuring probe on the element surface. The reinforcement image on radargram is a distortion of course contour lines in shape of hyperbola arms directed down the radargram.

The modern measurement systems do the automatic analyses of radargram, they connect the radargrams made close together in one image and they visualize reinforcement in construction in legible way for users. It is very often possible to do the special image of the structure with the reinforcement with the usage of the additional computer device. The radar devices still do not give transparently reinforcement diameters. It can be attempt to do the measurement in 3D model. However, in the world literature, it is seen between the forms of hyperbola seen on the radargram with the diameter of the reinforcement. It can be expected that the option to determine the reinforcement diameter would soon appear in the appliances offered on our market. However, the accuracy of the measurement method might be still a problem. Currently the accuracy of the cover measurement with radar method made by the best devices is defined as $\pm 5-10 \mathrm{~mm}$. 
In papers $[15,16,17,18,19,20,21]$ have been noticed that the shape of hyperbola describing the reinforcement on radargram depends on wave propagation speed $v$ time to passage of measuring probe above the testing reinforcement. The time of the measuring probe passage, it means the time from the moment when the device registers the reinforcement for the first time till the moment when it stops to register it. The speed of the wave propagation influences on hyperbola curve, but the time of the probe passage on the range of its arms. Knowing the parameter values $a$ and $b$ hyperbola $b$ (fig. 2), their relation with the reinforcement diameter $\phi$, wave propagation speed $v$ and time of probe passage $t_{0}$, on the tested reinforcement might be written as following:

$$
\begin{gathered}
a=t_{0}+\frac{\phi}{v}, \\
b=\frac{v}{2}\left(t_{0}+\frac{\phi}{v}\right) .
\end{gathered}
$$

The wave propagation speed $v$ and time to passage of the measuring probe registered by measuring device and parameters $a, b$ might be obtained from radargram. So nothing stand on the way to determine the reinforcement diameter $\phi$ from the formulas (5 and 6 ). The possibility of the usage this kind of method to determine the reinforcement has proved in work [22], where in the laboratory conditions obtained the measuring error of the steel pipes and cables diameters of $1.7 \div 5.3 \%$.

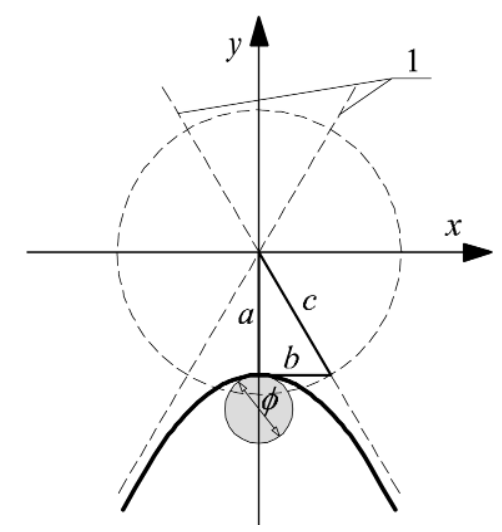

Figure 2. Assumptions to derivation of the formulas (5 i 6), 1 - hyperbola asymptotes

In work [23] different way of defining diameter has been presented. It has been adopted that the impulse distribution angle from the transmitting antenna is $90^{\circ}$ (fig. 3). With this assumption the rebar diameter might be determined without taking into account the wave propagation speed $v$ and time to passage of the measuring probe above the tested reinforcement. The diameter of the reinforcement $\phi$ might be determined according to:

$$
\phi=2 \sqrt{2} L-2 X-2 Y,
$$

where:

$L, X, Y$ - geometric data according to fig. 3 . 


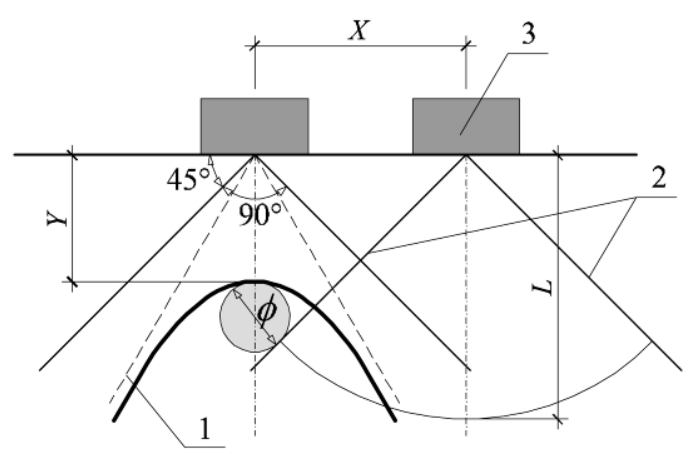

Figure 3. The principles to derivation of the formula (7), 1 - hyperbola asymptotes, 2 - the angle of impulse distribution from antenna, 3 - measuring probe

In works [24, 25] connecting the electromagnetic and radar advantages has been suggested. The tests were conducted on the specimens placed in pen and in concrete. The rebars diameter has been tested in rebar labs. It has been proved that the electromagnetic method does not give the correct test results because the reinforcement is placed too close together. On the basis of the conducted tests the empirical formulas have been developed for estimating the diameter of the touching rebars in the area of rebar lab. The diameter estimation accuracy has been obtained at the level of $2.35 \%$. It has to be noticed that the empirical formulas have some usage restrictions to the tested reinforcement and concrete.

To sum up, it has to be claimed that the advantage of the devices working according to the electromagnetic method is high accuracy within small depth of measurement. The disadvantage of those devices is small range of diameter measurement, limited to about $6 \mathrm{~cm}$. Radar devices have much bigger range (even to $75 \mathrm{~cm}$ ), however in the devices available on market there is no possibility of diameter measurement. In the world, there are some developing methods for diameter determining on the basis of radargram measurement obtained from the radar tests. Surely, the radar devices with the possibility of diameter measuring would appear on our market soon.

\section{Tested specimens}

In order to verify the accuracy of the NDT methods, some tests on widely used lintels made of AAC with a width of $b=180 \mathrm{~mm}$, height $h=240 \mathrm{~mm}$ and total length of $L=2000 \mathrm{~mm}$ were conducted. AAC of the elements has the strength of $f=4 \mathrm{~N} / \mathrm{mm}^{2}$. The detailed results of the material lintel research have been attached in works $[26,27,28]$. The lintel reinforcement was made of steel at yield point of $500 \mathrm{~N} / \mathrm{mm}^{2}$ ( B class, according to EN 1992-1-1:2008). Longitudinal rebars were at diameter of $8 \mathrm{~mm}$ (three rebars down and two rebars up). Longitudinal reinforcement in the form of open stirrups made of diameter rebars at $4,5 \mathrm{~mm}$. The stirrups were placed along the length in the fixed spacing of $150 \mathrm{~mm}$ (fig. 4). The longitudinal reinforcement and stirrups were heated and covered with corrosion-resistant coating made of resin.
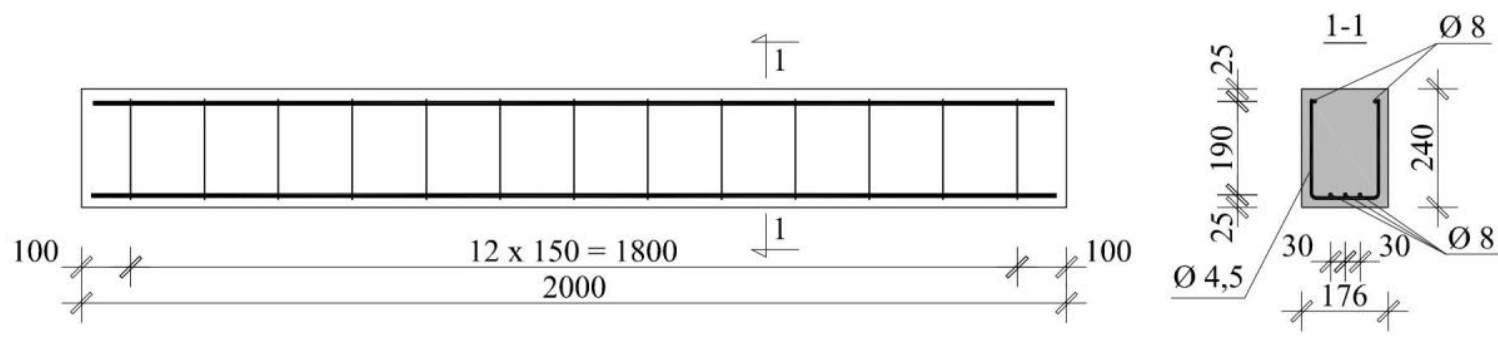

Figure 4. The beam used in tests 
Two beams were chosen to the tests. In order to make a precise location of the reinforcement, in the tested beams the both ends were broken down and the reinforcement was measured- fig. 5. In 11 places on the lateral surfaces and in 8 points (between the stirrups) from the bottom (at place of non-destructive testing measurements) made tiny openings (diameter $2 \mathrm{~mm}$ ) in order to measure the actual reinforcement cover $-c_{\text {obs }}$ with accuracy of $\Delta$ cobs $= \pm 0,1 \mathrm{~mm}$. Because the both beams location was the same the tests were conducted only on one of them.

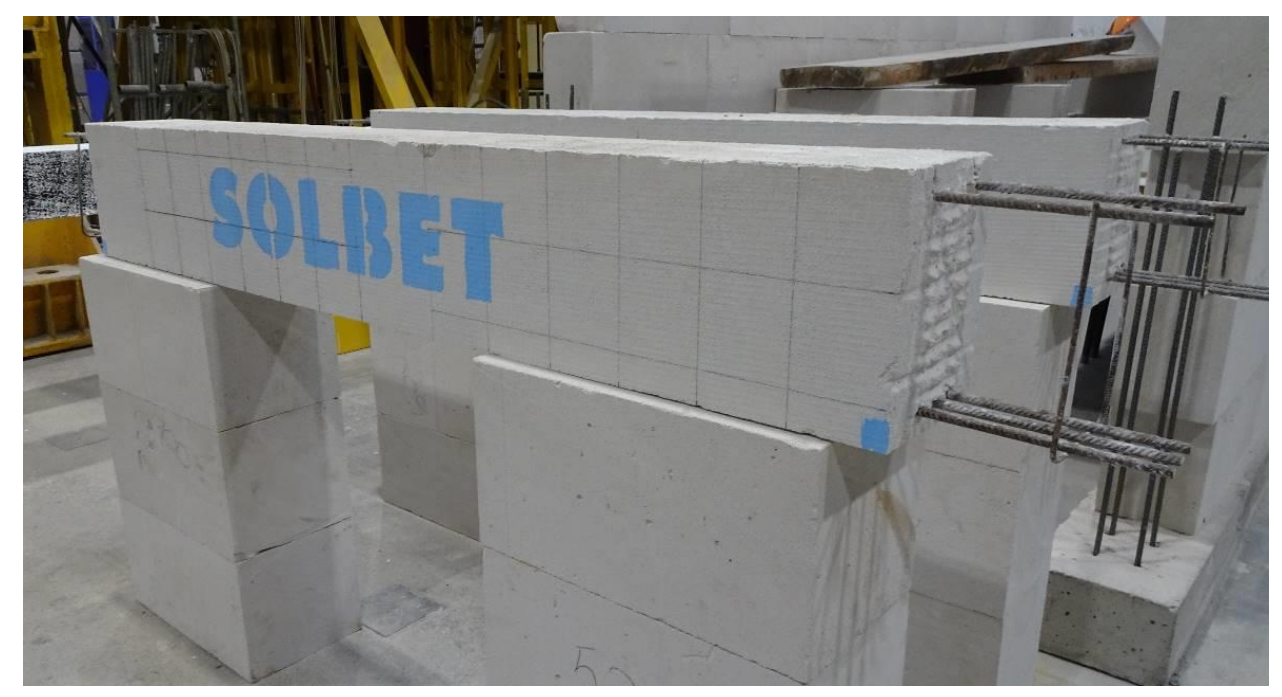

Figure 5. The view of the tested elements with the broken down reinforcement at the ends

\section{Applied research equipment}

The tests were conducted with the usage of two electromagnetic scanners and one GPR device. (fig. 6). The accuracy of the measurement depth of each device was the same, $\Delta \mathrm{cobs}= \pm 1.0 \mathrm{~mm}$. The tests were done with every device by scanning the same beams' places on the lateral surface and from the bottom. On the lateral surface rebars the stirrups' rebars were detected, but from the bottom the primary reinforcement has been tested. The tests were conducted with linear and surface scans. The places of the tests have been pointed on fig. 7 .

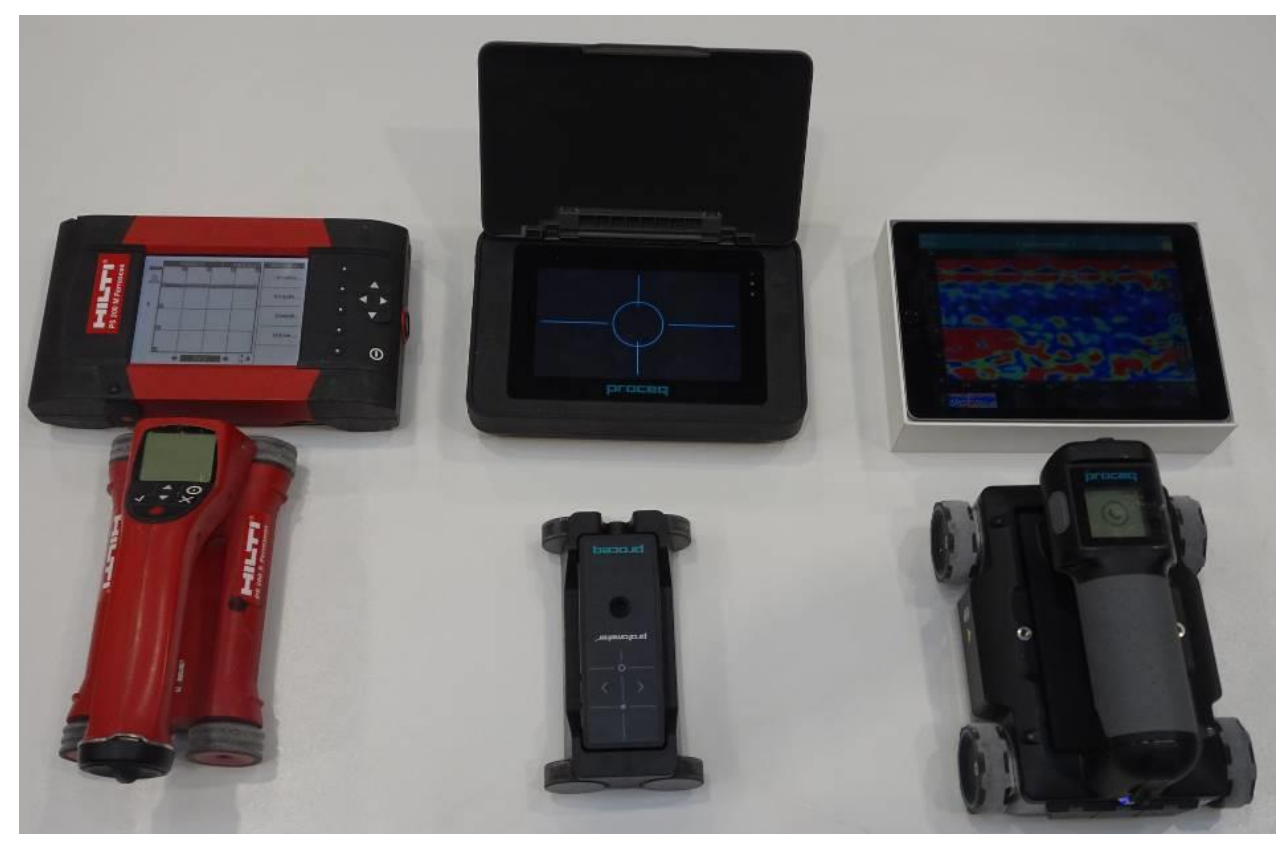

Figure 6. The view of devices used in tests, (a) electromagnetic device (1), (b) electromagnetic device (2), (c) radar device (3) 
a)

b)
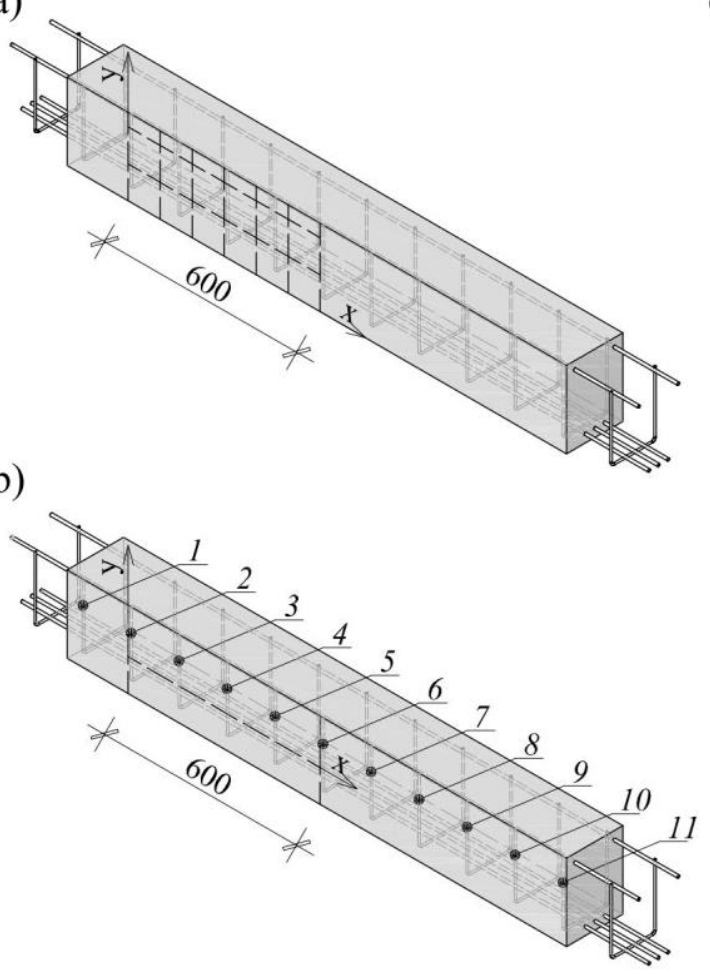

c)

d)
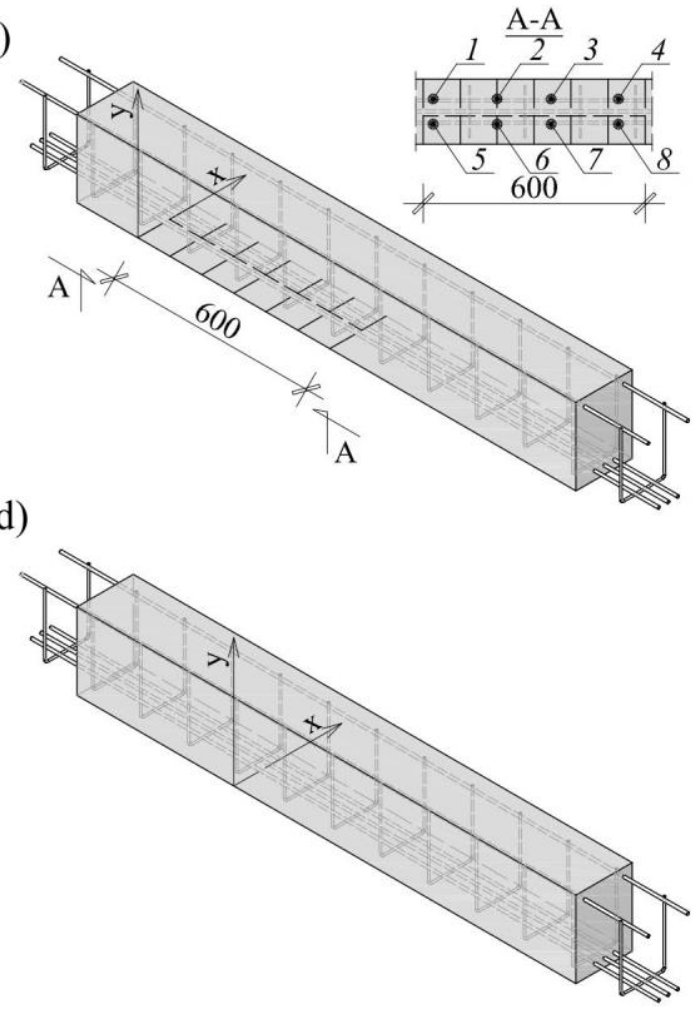

Figure 7. Places of the lintel tests: a) Stirrup tests - area scan, b) Stirrup tests - linear scan, c) main reinforcement test - area scan, d) main reinforcement test - linear scan

\section{The test results}

\subsection{Stirrup tests}

The stirrups tests made from the beam side, as the linear and surface scans. On the basis of linear scans only the reinforcement location might be determined (spacing and concrete cover). In fig. 8 has been shown the comparison of the linear scan example results done with electromagnetic devices and radar device (radargram). In fig. 9 were shown some surface scan examples done with electromagnetic device 1 and radar device 3.

The measurements result of 11 inner stirrups of the beam have been presented in table 1 along with the estimators of uncertainty according to [29]. Adopted that the uncertainty of calibration equals the accuracy of the particular devices but experimenter's uncertainty and random uncertainty has been missed. The actual average stirrups' cover was $c_{\text {obs }}=28.3 \mathrm{~mm}$, with the standard deviation $0.87 \mathrm{~mm}$ and coefficient of variation of $3 \%$. Estimated average reinforcement cover with the standard uncertainty was $3 \pm 0.3 \mathrm{~mm}$ (level of certainty $68.3 \%$ ), and the cover with taking into account the maximum uncertainty with the level of certainty $99.7 \%$ stood at $28.3 \pm 0.9 \mathrm{~mm}$. The reinforcement nominal cover was $C_{\text {nom }}=25 \mathrm{~mm}$, and executive deviation allowed by EN 13670 [30] norm was $\Delta_{\text {minus }}=10 \mathrm{~mm}$. The obtained result of the direct measurements was within determined limits. And with other methods obtained the average covers at $27 \mathrm{~mm}, 28.6 \mathrm{~mm}$ and $27 \mathrm{~mm}$, but standard and maximum deviations did not exceed $\pm 0.3 \mathrm{~mm}$ and $\pm 1.0 \mathrm{~mm}$. Obtained minimum covers measured with every NDT methods were bigger than minimum cover determined with taking into account dimension deviation. The reinforcement diameter was determined only with electromagnetic scanner 1 . The obtained result equal to $6 \mathrm{~mm}$, with the actual diameter at $4.5 \mathrm{~mm}$. However, the manufacturer declares the rebars location at diameter from $6 \mathrm{~mm}$. 
a)

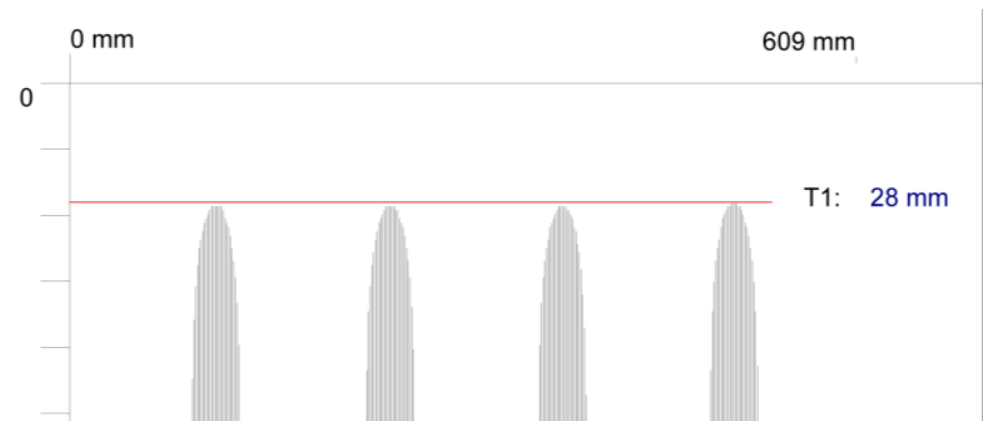

b)

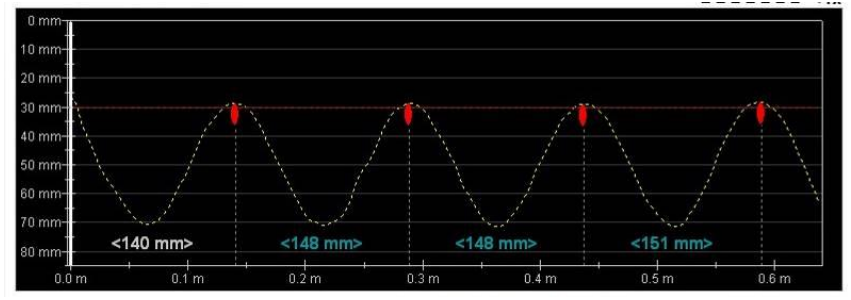

c)

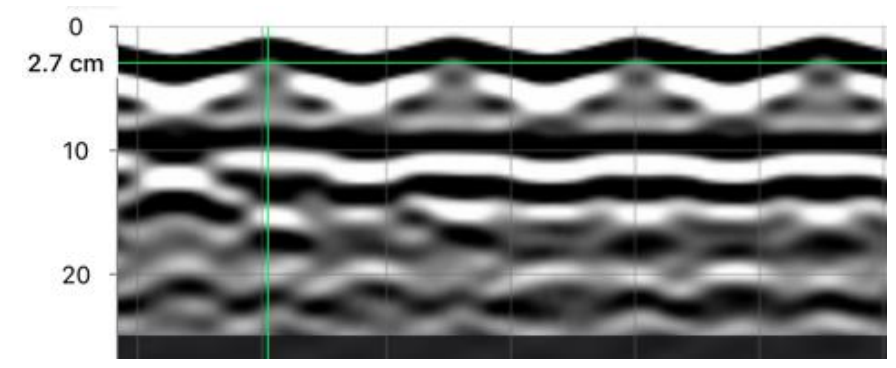

Figure 8. Linear scans with devices: (a) electromagnetic 1, average cover of the visible results- 27,8 $\mathrm{mm}$, (b) electromagnetic 2, average cover $-28,6 \mathrm{~mm}$, (c) radar 3, average cover $27 \mathrm{~mm}$

a)

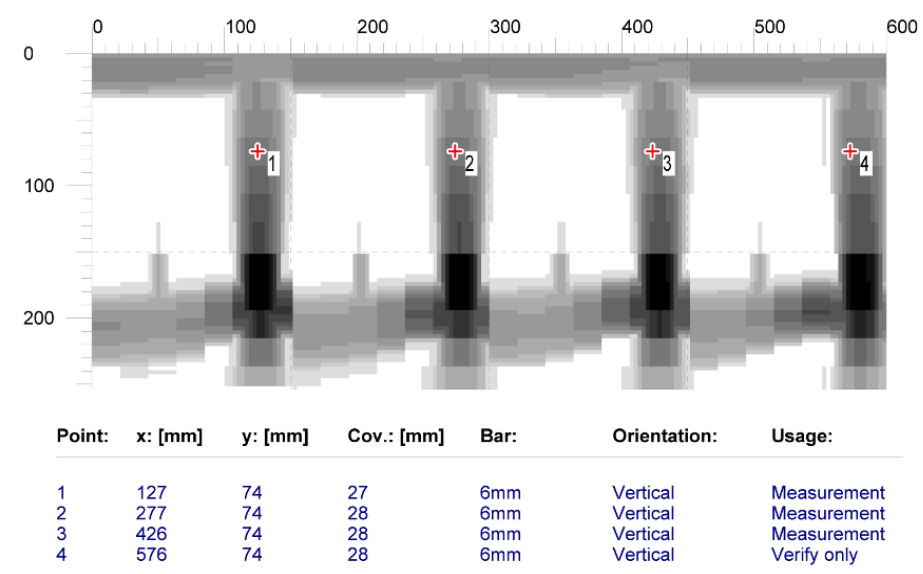

b)

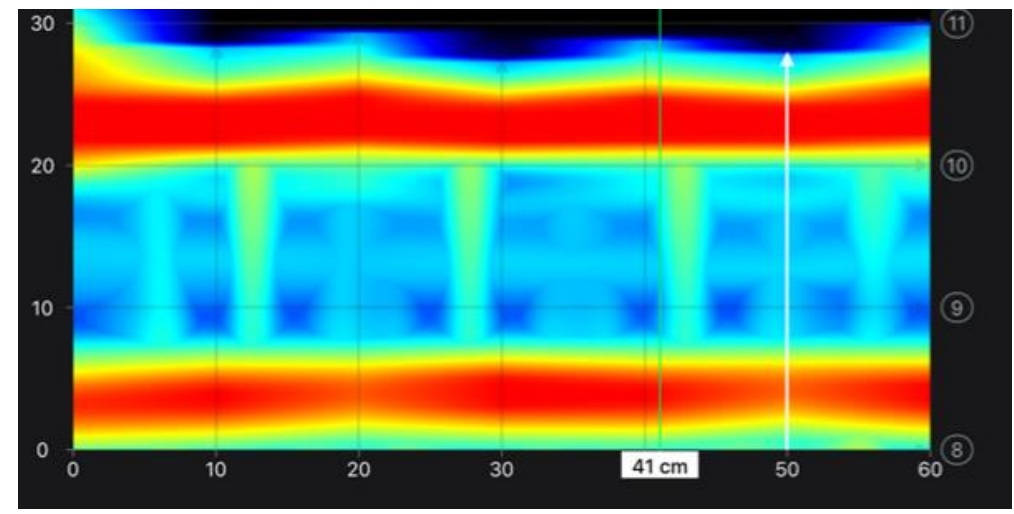

Figure 9. Surface scans with electromagnetic devices, (a) 1, average cover of the visible results- 27,8 $\mathrm{mm},(\mathbf{b})$ radar $3,-27 \mathrm{~mm}$ 
Table 1. The reinforcement stirrups measurement results made with each method

\begin{tabular}{|c|c|c|c|c|}
\hline \multirow[b]{2}{*}{$\begin{array}{l}\text { Number of measuring } \\
\text { point }\end{array}$} & \multicolumn{4}{|c|}{ Measured cover according to method, $\mathrm{mm}$} \\
\hline & Direct method, cobs & $\begin{array}{c}\text { Electromagnetic } \\
\text { device } \\
(1) \\
\end{array}$ & $\begin{array}{c}\text { Electromagnetic } \\
\text { device } \\
(2) \\
\end{array}$ & $\begin{array}{c}\text { Radar device } \\
\text { (3) }\end{array}$ \\
\hline 1 & 30.1 & 27 & 28.9 & 27 \\
\hline 2 & 28.1 & 28 & 28.6 & 27 \\
\hline 3 & 28.3 & 28 & 29.1 & 27 \\
\hline 4 & 28.2 & 28 & 28.1 & 27 \\
\hline 5 & 29.1 & 27 & 28.6 & 28 \\
\hline 6 & 27.3 & 27 & 28.2 & 27 \\
\hline 7 & 27.9 & 27 & 28.7 & 27 \\
\hline 8 & 26.9 & 28 & 28.3 & 27 \\
\hline 9 & 28.3 & 27 & 28.4 & 27 \\
\hline 10 & 28.2 & 27 & 28.6 & 27 \\
\hline 11 & 29.0 & 28 & 28.7 & 28 \\
\hline Average cover, cobs: & 28.3 & 27 & 28.6 & 27 \\
\hline Nominal cover, Cnom: & \multicolumn{4}{|c|}{$15 \mathrm{~mm} \leq$ Cnom $\leq 25 \mathrm{~mm}$} \\
\hline $\begin{array}{l}\text { Uncertainties of the } \\
\text { calibration } \Delta \text { cobs }\end{array}$ & 0.1 & 1.0 & 0.1 & 1.0 \\
\hline Standard deviation, s: & 0.87 & 0.52 & 0.30 & 0.40 \\
\hline $\begin{array}{l}\text { Standard deviation of } \\
\text { the mean value, } \\
\qquad \bar{s}=\frac{s}{\sqrt{n}}\end{array}$ & 0.3 & 0.2 & 0.1 & 0.1 \\
\hline $\begin{array}{l}\text { Standard deviation of } \\
\text { the calibration } \\
\qquad S_{d}=\frac{\Delta c_{o b s}}{\sqrt{3}}\end{array}$ & 0.1 & 0.6 & 0.1 & 0.6 \\
\hline $\begin{array}{l}\text { Standard uncertainty } \\
\qquad S_{c}=\sqrt{S_{d}^{2}+\bar{s}^{2}}\end{array}$ & 0.3 & 1 & 0.1 & 1 \\
\hline $\begin{array}{c}\text { Result with standard } \\
\text { uncertainty } \\
c_{m v} \pm S_{c}\end{array}$ & $28.3 \pm 0.3$ & $27 \pm 1$ & $28.6 \pm 0.1$ & $27 \pm 1$ \\
\hline $\begin{array}{l}\text { Maximum uncertainty } \\
\qquad \Delta c=\Delta c_{o b s}+3 \bar{s}\end{array}$ & 0.9 & 1 & 0.4 & 1 \\
\hline $\begin{array}{l}\text { Result with maximum } \\
\text { uncertainty } \\
c_{m v} \pm \Delta c \\
\end{array}$ & $28.3 \pm 0.9$ & $27 \pm 1$ & $28.6 \pm 0.4$ & $27 \pm 1$ \\
\hline Minimum cover $c_{\min }$ & 27.4 & 26 & 28.2 & 26 \\
\hline
\end{tabular}




\subsection{The primary reinforcement tests}

The aim of the primary reinforcement tests, made from the beam bottom, was to determine the size of the cover and primary reinforcement diameter and amount (diameters were determined only in case of electromagnetic scans). In fig. 10 the obtained results of electromagnetic tests comparison has been shown. The surface scan (fig. 10a), was done with electromagnetic device 1 and linear scan (fig $10 \mathrm{~b})$ with electromagnetic device 2 . Both devices do not give the correct number of rebars. The device 1 detected two rebars instead of three but it measured diameter quite correctly. However, the device 2 detected only one rebar and gave the diameter equal $18 \mathrm{~mm}$. The radar scanner 3 detected only one rebar in the linear scan as also in the surface scan. (fig. 11).

The measurement results have been presented in table 2 along with the estimators of uncertainty according to [29]. Adopted the same assumptions as with the stirrup uncertainty location analysis. There were some difficulties with the comparison of the measurement results with the actual results because every device detected the number of rebars less than it really was. Finally, adopted that the electromagnetic test results, device 1 (fig. 10a) were compared with the actual measurements made on the extreme rebars in the drillings made in places where the electromagnetic measurements were done (8 measurement points). In case of 2 and 3 devices, which detected one rebar, the value from drillings were compared with the value measured for one rebar. So in the measurement points 1 and 5,2 and 6, 3 and 7, 4 and 8 (fig. 10a) the same values were given in table 2 .

a)

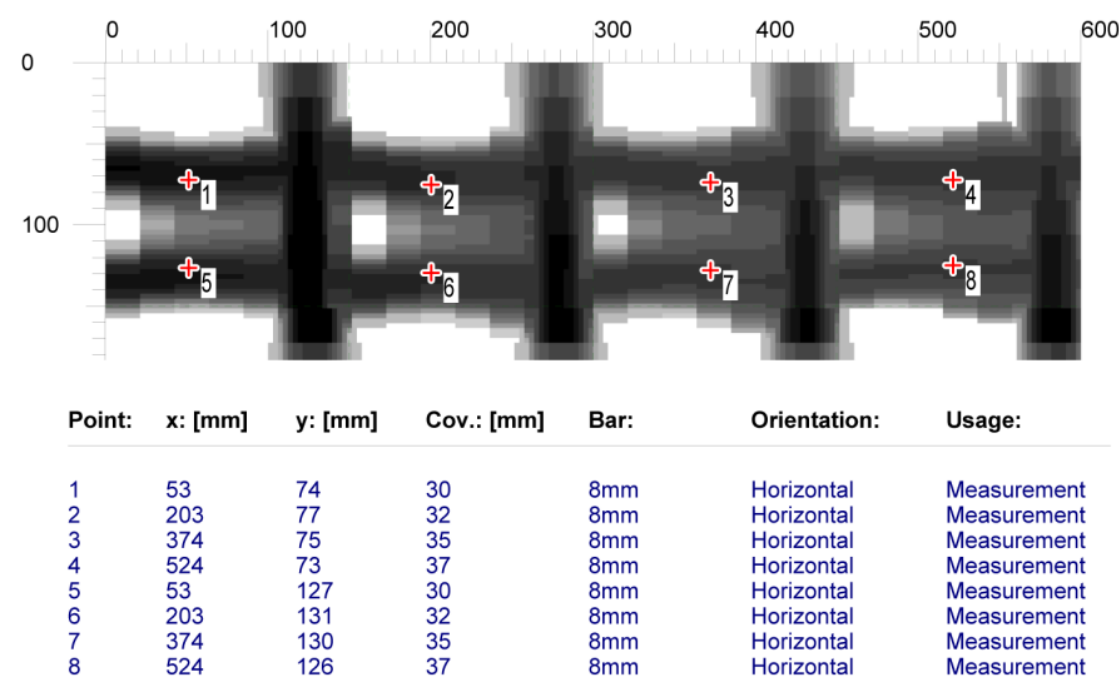

b)

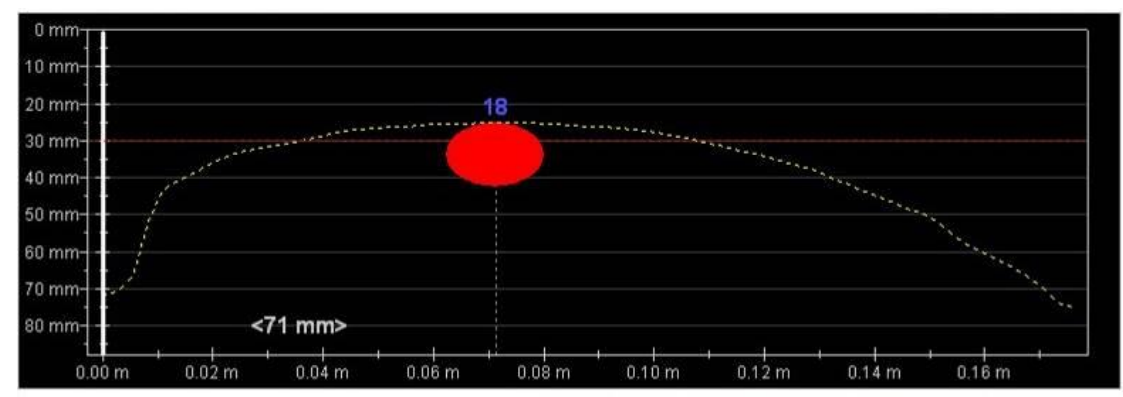

Figure 10. Electromagnetic devices scans, (a) device 1, two rebars detected, average cover of the visible results $-33,6 \mathrm{~mm}$, diameter 6-8 $\mathrm{mm}$, (b) device 2, one rebar detected, average cover of the visible results $-28 \mathrm{~mm}$, diameter $18 \mathrm{~mm}$ 


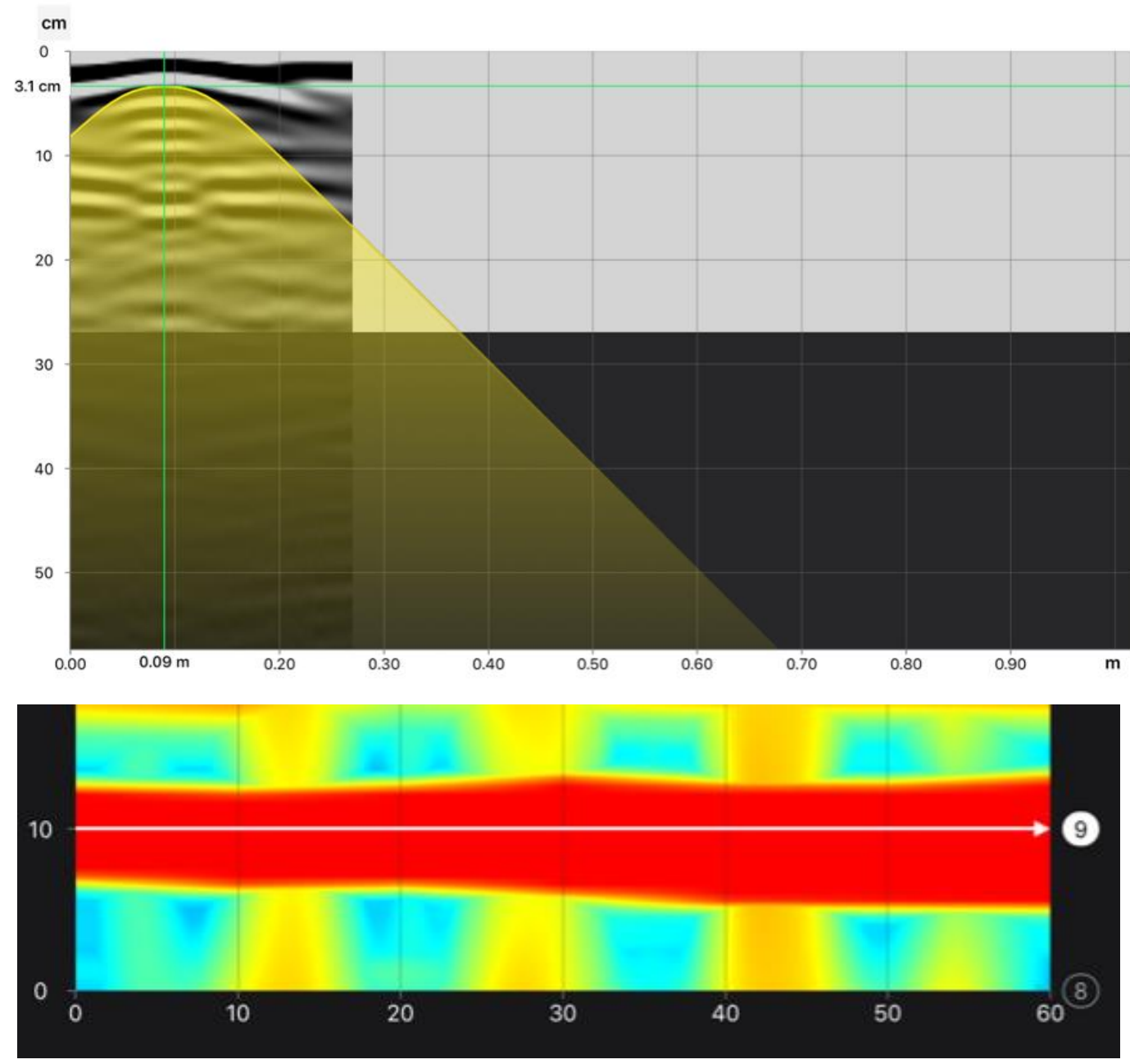

Figure 11. Scans of the radar device: 3 , one rebar has been detected, (a) linear scan (radargram), (b) surface scan

The average actual cover of the longitudinal rebars was $c_{\mathrm{obs}}=29,2 \mathrm{~mm}$, with the standard deviation at $0,7 \mathrm{~mm}$ and coefficient of variation of $2.4 \mathrm{~mm}$. Estimated average reinforcement cover with the standard uncertainty was $29.2 \pm 0,3 \mathrm{~mm}$ (level of certainty $68,3 \%$ ), and the cover with taking into account the maximum uncertainty with the level of certainty $99.7 \%$ stood at $29.2 \pm 0.8 \mathrm{~mm}$.

The reinforcement nominal cover was $C_{\text {nom }}=25 \mathrm{~mm}$, and executive deviation allowed by [30] norm was $\Delta_{\text {minus }}=10 \mathrm{~mm}$. So that, the obtained result of the direct tests was within determined limits. For the remaining methods, medium-sized covers equal $34 \mathrm{~mm}, 27.5 \mathrm{~mm}$ and $31 \mathrm{~mm}$ were obtained. Standard deviations mostly did not exceed $\pm 1 \mathrm{~mm}$, and maximum $\pm 4 \mathrm{~mm}$. Obtained minimum covers were bigger than minimum values taking into account the executive deviations.

In case of primary reinforcement tests (beam from the bottom) obtained much bigger deviations than in case of stirrup tests. (beam on the side). It must be emphasized that every device used in the tests did not detect the actual rebars number of the primary reinforcement. That is why, the result was burdened by a serious error resulted from the wrong reading of rebars' number by the research devices. 
Table 2. The measurement results of the primary reinforcement of every method

\begin{tabular}{|c|c|c|c|c|}
\hline \multirow[b]{2}{*}{$\begin{array}{c}\text { Number of measuring } \\
\text { point }\end{array}$} & \multicolumn{4}{|c|}{ Measured cover according to method, $\mathrm{mm}$} \\
\hline & Direct method, cobs & $\begin{array}{c}\text { Electromagnetic } \\
\text { device } \\
(1) \\
\end{array}$ & $\begin{array}{c}\text { Electromagnetic } \\
\text { device (2) }\end{array}$ & $\begin{array}{c}\text { Radar device } \\
\text { (3) }\end{array}$ \\
\hline 1 & 29.1 & 30 & 26.2 & 31 \\
\hline 2 & 28.8 & 32 & 27.3 & 30 \\
\hline 3 & 28.7 & 35 & 28.1 & 31 \\
\hline 4 & 29.2 & 37 & 28.4 & 32 \\
\hline 5 & 29.1 & 30 & 26.2 & 31 \\
\hline 6 & 28.9 & 32 & 27.3 & 30 \\
\hline 7 & 29.2 & 35 & 28.1 & 31 \\
\hline 8 & 30.9 & 37 & 28.4 & 32 \\
\hline Average cover, cobs: & 29.2 & 34 & 27.5 & 31 \\
\hline Nominal cover, cnom: & \multicolumn{4}{|c|}{$15 \mathrm{~mm} \leq C_{\mathrm{nom}} \leq 25 \mathrm{~mm}$} \\
\hline $\begin{array}{l}\text { Uncertainties of the } \\
\text { calibration } \Delta \text { cobs }\end{array}$ & 0.1 & 1.0 & 0.1 & 1.0 \\
\hline Standard deviation, $s$ : & 0.70 & 2.9 & 0.9 & 0.8 \\
\hline $\begin{array}{l}\text { Standard deviation of } \\
\text { the mean value, } \\
\qquad \bar{s}=\frac{s}{\sqrt{n}}\end{array}$ & 0.2 & 1.0 & 0.3 & 0.3 \\
\hline $\begin{array}{l}\text { Standard deviation of } \\
\text { the calibration } \\
\qquad S_{d}=\frac{\Delta c_{o b s}}{\sqrt{3}}\end{array}$ & 0.1 & 0.6 & 0.1 & 0.6 \\
\hline $\begin{array}{l}\text { Standard uncertainty } \\
\qquad S_{c}=\sqrt{S_{d}^{2}+\bar{s}^{2}}\end{array}$ & 0.3 & 1 & 0.3 & 0.6 \\
\hline $\begin{array}{c}\text { Result with standard } \\
\text { uncertainty } \\
c_{m v} \pm S_{c} \\
\end{array}$ & $29.2 \pm 0.3$ & $34 \pm 1$ & $27.5 \pm 0.3$ & $31 \pm 0.6$ \\
\hline $\begin{array}{l}\text { Maximum uncertainty } \\
\qquad \Delta c=\Delta c_{o b s}+3 \bar{s}\end{array}$ & 0.8 & 4 & 1.1 & 2 \\
\hline $\begin{array}{c}\text { Result with maximum } \\
\text { uncertainty } \\
c_{m v} \pm \Delta c\end{array}$ & $29.2 \pm 0.8$ & $34 \pm 4$ & $27.5 \pm 1.1$ & $31 \pm 2$ \\
\hline Minimum cover $c_{\mathrm{min}}$ & 28.4 & 30 & 26.4 & 29 \\
\hline
\end{tabular}

\section{Conclusion}

The conducted tests have proved the occurrence of the restrictions of both the most popular methods used for location the reinforcement in the structure. The devices are able to detect the rebars even of small diameters, on condition that, they are located in a large spacing. The reinforcement scanners have some difficulties with the correct defining number and diameter of rebars placed close together. 
The results obtained at range of measured covers with usage of electromagnetic and radar devices did not differ in terms of average value and in case of actual cover the differences did not exceed few percent. It has not been observed clear tendency which let to claim that one of the method distorts in artificial way indications, for instance due to the simplification for measurement method validation.

The works leading to connect both methods, consisting in connecting scans with the devices operating according to the electromagnetic and radar method, seem to be reasonable. Hybrid devices should let to do more accurate results, especially at range of diameter reinforcement measurement.

Acknowledgements: The authors would like to express particular thanks to Solbet Sp. z o.o. company, for supply of materials used during the research works. We would also like to thank Proceq and Viateco for providing research equipment.

\section{References}

1. Malhorta V.M., Carino N.J., Handbook on nondestructive testing of concrete, Second edition. CRC Press LCC, ASTM International, Boca Raton, London, New York, Washington D.C. 2004.

2. Bungey J.H., Millard S.G., Grantham M.G., Testing of concrete in structures, 4th edition, Taylor \& Francis, London and New York 2006.

3. Drobiec Ł., Jasiński R., Piekarczyk A. Diagnostic testing of reinforced concrete structures. Methodology, field tests, laboratory tests of concrete and steel. Wydawnictwo Naukowe PWN, Warszawa 2013. (in-Polish).

4. Hoła, J.; Schabowicz, K. State-of-the-art non-destructive methods for diagnostic testing of building structures-anticipated development trends. Archives of Civil and Mechanical Engineering 2010, 10, pp. $5-18$.

5. ISO/IEC, Guide 99:2007 International vocabulary of metrology - basic and general concepts and associated terms (VIM).

6. Chady, T.; Frankowski, P.K. Electromagnetic evaluation of reinforced concrete structure. Review of Progress in Quantitative Nondestructive Evaluation: Volume 32. 15-20 July 2012, Denver, Colorado, USA. AIP Conference Proceedings 2013, 1511. p.1355-1362

7. Drobiec, Ł.; Górski, M.; Krzywoń, R.; Kowalczyk, R. Comparison of non-destructive electromagnetic methods of reinforcement detection in RC structures. Challenges for Civil Construction CCC 2008, Porto, Portugal, 16-18 April 2008.

8. Szymanik, B.; Frankowski, P.K.; Chady, T.; Robinson, C.; Chelliah, A.J. Detection and Inspection of Steel Bars in Reinforced Concrete Structures Using Active Infrared Thermography with Microwave Excitation and Eddy Current Sensors. Sensors 2016, 16.

9. Frankowski, P.K.; Sikora, R.; Chady, T. Identification of rebars in a reinforced mesh using eddy current method. 42nd Annual Review of Progress in Quantitative Nondestructive Evaluation: Incorporating the 6th European-American Workshop on Reliability of NDE. 26-31 July 2015, Minneapolis, Minnesota, USA. AIP Conference Proceedings 2016, 1706.

10. Hola, J.; Schabowicz, K. Application of artificial neural networks to determine concrete compressive strength based on non-destructive tests. Journal of Civil Engineering and Management 2005, 11, pp. 23-32.

11. Sivasubramanian, K.; Jaya, K.P.; Neelemegam, M.; Covermeter for identifying cover depth and rebar diameter in high strength concrete. International Journal of Civil and Structural Engineering 2013, 3, pp. 557-563.

12. Lachowicz, J.; Rucka, M. Application of GPR method in diagnostics of reinforced concrete structures. Diagnostyka 2015, 16.

13. Lachowicz, J.; Rucka, M. 3-D finite-difference time-domain modelling of ground penetrating radar for identification of rebars in complex reinforced concrete structures. Archives of Civil and Mechanical Engineering 2018, 18, pp. $1228-1240$.

14. Agred, K; Klysz, G.; Balayssac, J.P. Location of reinforcement and moisture assessment in reinforced concrete with a double receiver GPR antenna. Construction and Building Materials 2018, 188, pp. 1119-1127.

15. Shaw, M.R.; Millard, S.G.; Molyneaux, T.C.K.; Taylor, M.J.; Bungey, J.H. Location of steel reinforcement in concrete using ground penetrating radar and neural networks. NDT\&E International 2005, 38, pp. 203-212 
16. Chang, C.W.; Lin C.H.; Lien, H.S. Measurement radius of reinforcing steel bar in concrete using digital image GPR. Construction and Building Materials 2009, 23, pp. 1057-1063.

17. Shihab S., Al-Nuaimy W., Radius estimation for cylindrical objects detected by ground penetrating radar. Subsurface Sensing Technologies and Applications 2005, 6, pp. 151-166.

18. Ristic, A.V.; Petrocacki, D.; Govedarica, M.; A New Method to Simultaneously Estimate the Radius of A Cylindrical Object and the Wave Propagation Velocity From GPR Data. Computers and Geosciences 2009, 35, pp.1620 1630.

19. Idi B.Y., Kamarudin M.N.: Utility Mapping with Ground Penetrating Radar: an Innovative Approach. Journal of American Science 2011, 7, pp. 644649.

20. Zanzi, L.; Arosio, D. Sensitivity and accuracy in rebar diameter measurements from dual-polarized GPR data. Construction and Building Materials 2013, 48, pp. 1293-1301.

21. Mechbal, Z.; Khamlichi, A. Determination of concrete rebars characteristics by enhanced postprocessing of GPR scan raw data. NDT\&E International 2017, 89, pp. 30-39.

22. Wei, J.S.; Hashim, M.; Marghany, M. New approach for extraction of subsurface cylindrical pipe diameter and material type from ground penetrating radar image. 31st Asian Conference on Remote Sensing 2010, ACRS 2010, vol. 2, 2010, s. 1187-1193.

23. Alhsanat, M.B.; Wan Hussin, W.M.A. A New Algorithm to Estimate the Size of an Underground Utility via Specific Antenna, PIERS Proceedings, Marrakesh, Maroko, 20-23 marca 2011, s. 1868-1870.

24. Wiwatrojanagul, P.; Sahamitmongkol, R.; Tangtermsirikul, S.; Khamsemanan, N. A new method to determine locations of rebars and estimate cover thickness of RC structures using GPR data. Construction and Building Materials 2017, 140, pp. 257-273.

25. Wiwatrojanagul, P.; Sahamitmongkol, R.; Tangtermsirikul, S. A method to detect lap splice in reinforced concrete using a combination of covermeter and GPR. Construction and Building Materials 2018, 173, pp. 481-494.

26. Drobiec, Ł.; Jasiński, R.; Mazur, W. Precast lintels made of autoclaved aerated concrete - test and theoretical analyses. Cement Wapno Beton 2017, 5, pp. 339-413.

27. Mazur, W.; Drobiec, Ł.; Jasiński, R. Research of Light Concrete Precast Lintels. Procedia Engineering 2016, 161, pp. 611-617.

28. Mazur, W.; Drobiec, Ł.; Jasiński, R. Research and numerical investigation of masonry - AAC precast lintels interaction. Procedia Engineering 2017, 193, pp. 385 - 392.

29. JCGM 100:2008 Evaluation of measurement data. Guide to the expression of uncertainty in measurement.

30. EN 13670:2011 Execution of concrete structures. 